\title{
MISERICORDIA \\ Y JUVENTUD UNIVERSITARIA
}

DOI: https://doi.org/10.52039/seminarios.v61i215.157

FRANCISCO JOSÉ VARELA*

«Nuestros centros educativos son un semillero, una posibilidad, tierra fértil para cuidar, estimular y proteger» (Papa Francisco. Quito, 7 de julio de 2015).

\section{LA VIRTUD DE LA MISERICORDIA}

Etimológicamente esta palabra viene del latín miseri-cor-dare y significa el amor del corazón que se da a la miseria. En los evangelios y, concretamente, en la carta de Pablo a los Filipenses (cf. Flp 4, 8-9), el Apóstol invita a esta comunidad a buscar la virtud en sus variadas formas: ante todo la caridad, $y$, a partir de ella, todo comportamiento bueno y edificante. En un mundo, el romano, donde el vicio era visto con normalidad (el vicio es lo contrario a la virtud) el cristiano nadaba contra corriente poniendo su mirada en todo aquello que, por ser bueno, contribuye a hacer bella la propia vida y a suscitar la esperanza del bien a todos. En la Escritura la caridad aparece siempre como la virtud más importante.

La Iglesia es hoy una plataforma para vivir la virtud, así nos lo enseña el Papa Francisco destacando el ejercicio de la misericordia como una de las mejores virtudes, de hecho lo ha tomado como el eje central de su pontificado: «Un aspecto particular de la maternidad de la Iglesia es que ella nos educa a través de las obras de misericordia. Como buena madre y educadora, ella se fija en lo que es esencial; y lo esencial, según el Evangelio, es la misericordia. Pero la enseñanza de la Iglesia no es algo meramente teórico, no da lecciones, sino que se transmite con el ejemplo. Ella nos ofrece el ejemplo de los santos, pero también el de tantos hombres y mujeres sencillos. La Iglesia nos enseña a dar de comer y beber al que tiene

* Francisco José Varela Lozano es el delegado de Pastoral Universitaria de la Diócesis de Tuy-Vigo. 
hambre y sed; vestir al que está desnudo. Nos enseña a estar cerca del enfermo, ya sea en un hospital, en una residencia o en la propia casa. Nos enseña a visitar al encarcelado, mirándolo en su humanidad, pues sólo la misericordia puede cambiar el corazón y hacer que una persona vuelva a insertarse en la sociedad. Por último, la Iglesia nos enseña también a estar cerca del abandonado o del que muere solo. No basta con amar sólo al que nos ama. Para cambiar el mundo es necesario hacer el bien a quien no puede darnos nada a cambio, como Dios Padre hizo con nosotros entregándonos a Jesús» (Audiencia 10 Septiembre 2014).

\section{LLAMADOS POR EL PAPA A SER MISERICORDIOSOS}

El lema elegido por el Papa para su pontificado es la frase «miserando atque eligendo», tomada de una homilía de Beda el Venerable (672-735) comentando un capítulo en el que Jesús mira al publicano (Mateo) con misericordia y eligiéndolo le dice que le siga. Todos los gestos que, hasta ahora, el Papa está teniendo apuntan a vivir esta actitud de agradecimiento que es la misericordia. Es, precisamente, en el evangelio de Mateo (Mt 5,7 ) donde se nos promete «felices los misericordiosos porque alcanzarán misericordia»; la misma vivencia, el mismo ejercicio de la misericordia es ya el premio prometido por Jesús; esto el Papa lo vive y es lo que continuamente nos quiere transmitir, no se trata, pues, de una «política de gestos», se trata de ejercer la misericordia de tal manera que los creyentes vivamos ya la misma vida de Dios. En el sentido bíblico la misericordia es el ser mismo de Dios cf. Ex 3, 14; 33, 19). Lo que hace el Papa Francisco cuando visita a los emigrantes de Lampedusa, a las favelas de Río, o a los presos de Roma, no es algo novedoso, es continuar con la auténtica y verdadera tradición de la Iglesia, continuar con el auténtico legado de Jesús; la renovación del Papa es la renovación de quien ejerce la misericordia porque él mismo ha sido destinatario, también, de ella. Cuando el Papa fue creado Cardenal escribió que «la misericordia cambia el mundo, hace al mundo menos frío y más justo». El Papa sabe muy bien que lo que a los cristianos nos hace dignos de crédito es nuestro ejercicio de la misericordia, ese mismo ejercicio que enrojeció al Papa cuando Francisco de Asís le visitó y se arrodilló ante él. En el Papa Francisco todo nace de una convicción que en realidad siempre ha tenido la misma Iglesia, la de que Dios se revela a los sencillos y humildes de corazón. Ésta es sin duda la razón por la que Francisco enfatiza el ejercicio de la caridad con quienes más sufren, por esto nos ha mandado salir «a las periferias» de nuestra existencia. 
En los Ejercicios Espirituales que el Cardenal Bergoglio dio a los obispos españoles en enero de 2006, el hoy Papa comenzaba con este precioso texto de Lucas: «Nos mueve antes que nada el deseo de dar gracias a Dios y de alabarle, porque, en medio de todo, 'su misericordia llega a sus fieles de generación en generación' (Lc 1, 50)». Toda acción de gracias funda nuestra memoria en la misericordia del Dios que nos sostiene. El Padre Bergoglio recordaba cómo «es notorio en el Evangelio que el Señor alerta y reprende más a los que le son más cercanos: a los discípulos y entre ellos especialmente a Pedro. Y lo hace como para que quede claro que el ministerio es pura gracia, que no depende de los méritos del elegido para la misión, y que ser corregido una y otra vez en ese ámbito de la elección gratuita y de la fidelidad definitiva por parte del Señor es signo de mayor misericordia. De la mano de la reprensión del Señor viene su misericordia abundante. Dios siempre nos ha enseñado que se urge lo que debe ser perfeccionado y curado». El mismo Papa Francisco destaca unos elementos que identifican la acción misericordiosa de Dios. Estos elementos luego nos servirán a nosotros para actuar, para identificarnos con Cristo.

\section{LOS ELEMENTOS DE LA MISERICORDIA DIVINA}

Acercamiento. El Señor no pone límites al acercamiento de la gente. Él es el prójimo por excelencia, el que viene, el Dios con nosotros, el Dios que estará con nosotros todos los días hasta el fin del mundo.

Pensamiento en Dios. Nuestro Dios es celoso de nuestro recuerdo para con Él, tan celoso que a la menor señal de arrepentimiento se vuelve misericordioso. Y esa memoria también nos hará misericordiosos porque oiremos en nuestro corazón esa gran verdad: «Recuerda que fuiste esclavo en la tierra de Egipto» (Dt 15, 15).

Capacidad de resistencia. «Vosotros ahora sentís tristeza; pero volveré a veros, y se alegrará vuestro corazón, y nadie os quitará vuestra alegría» (Jn 16, 22). El verdadero gozo se fragua en el trabajo. El gozo que no ha sido «probado» no deja de ser un simple entusiasmo que no puede ser fecundo. En la cruz está la misericordia y el arrepentimiento.

La paz, el fruto de la misericordia. Solo quien ha recibido misericordia puede ser misericordioso. La paz se enraíza por el consuelo. Solo sabe consolar quien primero se ha dejado consolar. La misericordia nos hace apacibles, comprensivos y conciliadores ${ }^{1}$.

1. Cf. J. M. Bergollo, En Él solo la esperanza, Madrid 2013. 
El acercamiento es la actitud primera y más importante en el ejercicio de la misericordia. No puedo ser misericordioso a distancia, tengo que acercarme.

\section{EL VOLUNTARIADO COMO FORMA JOVEN DE ACERCAMIENTO}

El voluntariado es una llamada a vivir la solidaridad como estilo de vida diferente, ofreciendo alternativas para que todas las personas tengan acceso a una vida digna y puedan desarrollarse plenamente; es fundamental, pues, el modo. El ejercicio del voluntariado ofrece al joven universitario la oportunidad de crecer como persona en el ejercicio concreto de la misericordia. Repito las palabras del Papa: para cambiar el mundo es necesario hacer el bien a quien no puede darnos nada a cambio, y el bien lo hago acercándome a quien más me necesita.

La Iglesia desde su acción caritativa y social quiere un modelo concreto de joven voluntario: quiere un joven sensible hacia lo social; que vive la solidaridad y la caridad como algo inseparable de la justicia y de los derechos humanos; que se compromete de forma desinteresada y gratuita a poner sus capacidades y su tiempo al servicio de las necesidades de los más pobres, excluidos y vulnerables; que sabe acoger a las personas respetando su libertad individual, y despertar en ellas la capacidad de ayudarse a sí mismas; que es capaz de establecer una buena relación personal y trabajar en equipo; que asume tareas adecuadas a sus aptitudes, posibilidades y preparación; que es consciente de la necesidad de actualizar su formación para adecuar la tarea que va a realizar a las circunstancias y características de las personas necesitadas, y muy consciente de que su acción es educativa y promotora de cambio social, denunciando, si cabe, situaciones sociales de exclusión e injusticia (cf. Cáritas).

Está claro que el Evangelio no se ha escrito para quietos o mortecinos, sino para personas industriosas, con capacidad de resistencia y con fuerza para actuar; un joven con inquietudes de ayudar a los demás es el destinatario perfecto para esta misión: hacer un mundo más justo.

La mayoría de los jóvenes que acuden hoy en día a la Universidad van a buscar un estatus, un futuro prestigio social. En cualquier caso, todos esos jóvenes van a ser los transformadores de la sociedad, para bien o para mal. Los estudios deberían llevar a todos esos chicos y chicas a solidarizarse con los más pobres. La Universidad como comunidad educativa desempeña un papel fundamental en la construcción de la ciudadanía y de la cultura; es, por lo tanto, absolutamente necesario crear en el ámbito 
universitario espacios de búsqueda, incluso generando debate que nos transporte hacia lo concreto. Se hace urgente enseñar a pensar qué tipo de cultura es el que queremos para nosotros y qué tipo de sociedad aspiramos a dejar a quienes vienen detrás.

El voluntariado universitario es una acción concreta, real, que nos ayuda a salir de nosotros mismos, que nos mueve del egoísmo al altruismo, que nos sitúa en la realidad de los últimos de la sociedad y nos impulsa a reflexionar sobre la escala de valores que vivimos y queremos vivir. El voluntariado es una oportunidad para ejercitar la misericordia; $y$, para los alejados de la fe, una oportunidad de conocerla en su esencia, porque creer es servir. Acercarse no es fácil. Es necesaria, como dice el Papa Francisco, una cierta capacidad de resistencia, ser fuerte en la adversidad para así poder transmitir ternura a quien lo necesita; parece contradictorio, pero la fortaleza y la ternura deben ir juntas para lograr el objetivo. Esto lo sabía muy bien la Madre Teresa de Calcuta. Quien se ha acercado a las personas, quien las ha servido, quien ha vivido la experiencia de socorrerlas, quien ha sentido su ternura, quien se ha esforzado por suscitar una sonrisa en medio del dolor, quien ha transmitido esperanza en el desierto interior, en definitiva, quien ha ejercido la misericordia no es ya la misma persona; el ejercicio de la misericordia tiene el poder de cambiar a las personas no solo a las receptoras, sino principalmente a las que dan, a las que ejercitan esta virtud; es una virtud tan poderosa que quien ha sido receptor de la misericordia será ya misericordioso. Los jóvenes que se comprometen en servir a las personas son, sin duda, lo mejor de nuestra sociedad. Por esta razón cuando un joven se está formando en la Universidad debe tener la oportunidad de ayudar y es una obligación de la Iglesia estar presente y ofrecer oportunidades de servicio.

EL DIOS SERVIDOR Y MISERICORDIOSO COMO REFERENCIA DECISIVA PARA EL JOVEN CREYENTE

Ciertamente no todos los jóvenes que se comprometen lo hacen desde el convencimiento de la fe; pero los jóvenes cristianos, los que no están alejados de la fe, tienen su modelo de servicio en Jesucristo. Quiero subrayar la escena del lavatorio de los pies, escena inseparable de la Eucaristía, como el ejemplo de misericordia de Dios para con nosotros. Creo no exagerar nada al decir que la mejor forma de conocer a Dios, de identificarnos con Él, es desde el lavatorio de los pies. El rostro más auténtico de Cristo es el que se refleja en el agua del barreño. 
En esta sociedad del éxito en la que vivimos resulta igual de difícil ser servido como servir, porque tanto conservadores como revolucionarios ponemos nuestro corazón en la acción y en el éxito, creemos únicamente en el dios de la acción, el dios fuerte, poderoso. Este dios solo impresiona la fe que tiene éxito. Para un cristiano así, el que sufre es un enfermo, el que llora es débil y demuestra falta de fuerza. El Dios crucificado, el Dios que se arrodilla para lavar unos pies, se contradice con el dios de la sociedad exitosa, con el dios del que acaba su vida rico, después de haber realizado una carrera exitosa.

Esta bellísima escena del lavatorio de los pies nos pone en relación con la muerte y Resurrección del Señor. Cuando Jesús se quita el manto y vuelve a ponérselo al final (cf. Jn 13,12) indica la entrega de su persona y la vuelta a la vida; Jesús se desprende de su vida y la recobra (Jn 10, 17). Aquí la palabra «manto» no simboliza el poder, sino que se identifica con la persona de Jesús; ambas interpretaciones son ciertas y complementarias ${ }^{2}$. Cuando san Ignacio de Loyola contempla esta escena en sus ejercicios espirituales antes de la Pasión es por algo. Aquí está la clave: arrodillarse, quitarse el manto, lavar los pies, no es solamente un gesto de humildad de Jesús, es entregar total y radicalmente toda la vida al servicio del amigo, del hermano. Por esto el lavatorio está en el Jueves Santo, por esto después del lavatorio viene la cena, porque en la Eucaristía Cristo se nos da en alimento totalmente, y celebramos su muerte y resurrección. El lavatorio da el sentido auténtico a la Eucaristía, donde Él se nos ofrece realmente.

Hay unas palabras de Hans Urs von Balthasar que los cristianos deberíamos tener siempre presentes: «El amor no quiere otra recompensa que el amor recíproco; por eso, Dios, para su amor, no pretende de nosotros otra cosa que nuestro amor, -no de palabra ni con frases, sino con obra y verdad (cf.1 Jn 3, 18)-, quien no conoce el rostro de Dios por medio de la contemplación, no lo podrá reconocer en la acción» ${ }^{3}$. Y yo añado que para contemplar el rostro de Dios debemos dejar que nos lave los pies, y mirar hacia el agua. Queda claro, pues, que el ejercicio de la misericordia es difícil porque implica un salirse de uno mismo y caminar hacia el otro y no solo para contemplarle. A mi juicio esta convocatoria del Año de la Misericordia nos viene a todos muy bien; el aburguesamiento ha apagado nuestra acción apostólica; es una verdadera pena observar como el ¿98 \%?

2. Cf. J. Mateos - J. Barreto, El Evangelio de Juan, Madrid 1982, 591.

3. Cf. H. U. von Balthasar, Solo el amor es digno de fe, Salamanca ${ }^{3} 2011,101$. 
de los católicos podrían denominarse cristianos de «misa dominical». Su compromiso creyente se reduce a escuchar (que no participar) la misa, comprar el pan y tomar el vinito en la cafetería que hace esquina con la iglesia; y los más jóvenes cantar en la misa, tocar la guitarrita y hasta otra ocasión, si es que apetece. Me pregunto ¿dónde está ese compromiso que hace que nos sintamos orgullosos de nuestra fe y de nuestra Iglesia?. ¿Vivimos los valores permanentes que vivió Jesús de Nazaret? Cristo ha dado la cara por nosotros, ¿la damos nosotros por él?

\section{LA MISERICORDIA COMO ACTITUD}

La misericordia no es un sentimiento, es una actitud; implica en cada uno de nosotros un movimiento, una acción y eso, además, no se improvisa, implica una preparación interior y unas cualidades personales; me permito señalar someramente tres.

\section{Actitud de perdón}

El Evangelio nos dice que tenemos que perdonar «hasta setenta veces siete», es decir, siempre. Esto significa dejarnos llevar por la compasión del corazón. Por experiencia sabemos que perdonar no es fácil. Quizá a nosotros y a «nuestra justicia» nos resulta muy difícil comprender la facilidad con la que perdonaba Jesús y la facilidad con la que olvidaba, eso es porque el amor de Dios no es excluyente, por eso es amor. Decir esto: que el amor no es excluyente, supone aludir a la experiencia de solidaridad (recordamos el voluntariado) como la determinación firme y perseverante de empeñarnos por el bien común de todos y de cada uno. «La entrega por el bien del prójimo, que está dispuesto a 'perderse', en el sentido evangélico, por el otro en lugar de explotarlo, y a 'servirlo' en lugar de oprimirlo ${ }^{4}$,esto es la solidaridad y es así como actuó Jesús de Nazaret al acercarse a la adúltera de la que nos habla san Juan en el Evangelio. No tengamos miedo a pedir perdón. Dios sabe y comprende la intrínseca fragilidad de los propósitos humanos, Dios sabe de la mutabilidad de las circunstancias externas, Dios sabe de perdón. Dios se pone a nuestra disposición: su omnipotencia a mi flaqueza, su justicia a mi inquietud, su bondad a mi malicia. Él pone de su parte lo que puede y nosotros debemos poner de la nuestra lo que podamos (no olvidemos como acaba el pasaje de la adúltera: «Vete y no

\section{Juan Pablo II, Preocupación por los problemas sociales.}


peques más», le dice Jesús; lo que supone para ella, también, un esfuerzo personal). Es preciso, por nuestra parte, atravesar las aguas violentas de los apegos. $Y$ « ¿qué es un apego? Es una necesidad compulsiva que embota tu sensibilidad, una droga que enturbia tu percepción. Por eso, mientras tengas el más mínimo apego hacia cualquier cosa o persona, no puede nacer el amor. Porque el amor es sensibilidad, y la sensibilidad se destruye cuando resulta dañada, aunque sea mínimamente. Del mismo modo que el funcionamiento defectuoso de una pieza esencial de un sistema de radar distorsiona la recepción y falsea la respuesta a lo que se percibe ${ }^{5}$. Si queremos llegar al amor, y esto solo lo conseguiremos por la sensibilidad.

Nos gusta mucho y en ocasiones juzgamos a las personas por lo que aparentan ser y no por lo que son. Nos gusta encasillar. Y, sin embargo, tenemos que decir que en el cielo no hay enchufes (tampoco hacen falta); ahí, ante Dios, las apariencias no engañan. Cuando Jesús de Nazaret defiende y perdona a los publicanos y a las prostitutas (cf. Mt 21,28 ) no está atacando, entendámoslo bien, a los cumplidores piadosos por el hecho de ser piadosos; ni demostró sus preferencias a los pecadores como si el pecado fuera una virtud, esas actitudes de Jesús no son un canto a la inmoralidad, sino un elogio a la sinceridad. Jesús justifica al publicano que reza frente al fariseo cumplidor sencillamente porque el publicano le dice: Señor, lo bueno que hay en mí es obra conjunta de tu gracia y mi esfuerzo; lo malo es exclusivamente mío (cf. Lc 18, 9-14). Jesús perdona y pone sus ojos en el sincero de corazón, en quien más reconoce necesitarlo. Como al publicano o a la prostituta Dios nos ama y expresa su amor con su salvación, Dios nos «salva» permanentemente desde nuestro reconocimiento de ser pecadores. Solo sabe perdonar quien se ha sabido perdonado. Pero claro, perdonar no es fácil.

\section{Actitud de agradecimiento}

La gratitud supone una mirada retrospectiva, un mirar atrás, observar el camino andado, y dar gracias por todo lo recibido. Es pues, una actitud, y no un acto aislado y concreto. Es una actitud asumida y no vacía, porque me llena. Si recordamos la curación de los leprosos por parte de Jesús (cf. Lc 17, 11-19) vemos que, de todos los que curó, solo uno regresa para darle las gracias, solo regresa el que se considera «curado», el que 
se considera «salvado». En definitiva, solo el que regresa, es consciente de la "gracia» recibida, y, por eso, vuelve a mirar a Cristo a la cara para decirle "gracias». Esa es la actitud que Dios nos pide, a eso me refiero cuando hablo de una mirada retrospectiva a nuestra vida. Creo, honestamente, que si verdaderamente fuésemos conscientes del amor que Dios nos tiene viviríamos de otra forma; si fuéramos conscientes de que somos privilegiados porque Dios nos honra con su amistad, nuestras actitudes ante nosotros mismos, ante los demás, ante la vida, serían otras. ¿Nos hemos preguntado en algún momento cuántas veces damos las gracias y por qué? ¡Cuando hablo con jóvenes que han vivido una experiencia fuerte de servicio a los demás, todos, absolutamente todos, se sienten agradecidos, han recibido más de lo que han dado y mayor es el agradecimiento cuanto más dura y difícil ha sido la experiencia de servicio, que, ciertamente, nunca está exenta de dolor.

\section{Actitud de alegría}

Junto a estas dos actitudes -y experiencias- de perdón y agradecimiento, está siempre presente la de la alegría; el servicio al otro va siempre acompañado de la alegría. Un joven comprometido no es un joven triste; al contrario, vive y es feliz, y su mirada refleja siempre la alegría. El mismo Papa Francisco, en la Bula del jubileo, hace un llamamiento a ser «misioneros de la alegría».

Cuando contemplo y escucho las experiencias de los jóvenes universitarios comprometidos en acciones de voluntariado, es decir, en acciones de servicio a los demás, la alegría profunda, esa que nace de la felicidad interior, es una realidad, y digo más, es contagiosa. No conozco a ningún joven "servidor» triste. Una de las obras de misericordia espirituales es "consolar al triste», ¿cómo lo voy a hacer desde la tristeza?

La alegría no es solamente signo de inteligencia, también de santidad. san Juan Bosco hacía consistir la santidad en estar siempre alegre; así se lo repetía continuamente a su joven alumno Domingo Savio. Desgraciadamente todavía quedan muchos cristianos que viven la fe como «angustia», todavía hay muchos que no han sabido «hacerse como niños», no se trata aquí de infantilizarnos, sino de recuperar el rasgo de la alegría. Los jóvenes cristianos, especialmente, están llamados a transformar las horas tristes de la vida. Jesús comparó el Reino de Dios con un banquete de bodas, ¿quién está triste en un banquete de bodas? La alegría es una actitud de todo creyente, y no digamos de todo joven creyente. 
Mı PETICIÓN FINAL A JÓVENES VALIENTES

Deseo terminar mi somero artículo con una cita del profeta Isaías y dos peticiones.

Dice Isaías: «Voy a recordar la misericordia del Señor, y todos los motivos que tenemos para alabarlo: todo lo que hizo por nosotros el Señor y la generosidad que ha mostrado a su gente. Todo lo que ha hecho por amor, en su inmensa bondad. Él se convirtió en su salvador en las dificultades: no ha delegado en nadie para venir en su ayuda, ni en mensajeros, ni en enviados, sino que ha sido su presencia misma la que los salvó. Por su amor y su compasión los rescató y los liberó. Se hizo cargo de ellos, los levantó del suelo y los tomó en sus brazos» (cf. Is 63, 7-9).

Mi primera petición nace de una gran verdad: solo puede «salvar» quien ha sido antes salvado. No tengamos nunca miedo a pedir perdón.

Mi segunda petición: Tomemos como prioridad en nuestra vida levantar del suelo y tomar en nuestros brazos a quien está tirado. 